\begin{tabular}{l} 
SCIENCE \& TECHNOLOGY \\
Journal homepage: http://www.pertanika.upm.edu.my/ \\
\hline PERTANIKA
\end{tabular}

\title{
Surface Treatment of Cement based Composites: Nano Coating Technique
}

\author{
Isam Mohamad Ali ${ }^{1}$, Tholfekar Habeeb Hussain ${ }^{2}$ and Ahmed Samir Naje ${ }^{2 *}$ \\ ${ }^{1}$ Karbala Technical Institute, Al-Furat Al-Awsat Technical University, 56001 Karbala, Iraq \\ ${ }^{2}$ College of Water Resources Engineering, Al-Qasim Green University, Babylon, Iraq
}

\begin{abstract}
Geometry, size, and shape of the surface pores, as well as, capillarity, and exposure environment are directly influence strength and durability of cementitious composites. The current research aimed to improve the resistance to abrasion and decrease the surface porosity of cement-based composites by nano surface coating technique. All samples were coated with a mixture of methanol alcohol, ordinary Portland cement and nano powder of $\left(\mathrm{TiO}_{2}, \mathrm{MgO}, \mathrm{ZnO}\right.$ and $\left.\mathrm{ZrO}_{2}\right)$ separately in percentages of $(1,1.5$, and $2 \%)$ by weight of cement. The hardness, abrasion, water absorption, density, porosity, and microstructural analysis: Scanning Electron Microscopy and X-Ray Diffraction (SEM \& XRD) were studied for all coated and control specimens. Results showed an improvement in mechanical properties for all coated specimens as compared to control. The highest Vickers micro hardness value had reached $29 \%$, while the largest value of abrasion resistance had increased by $39 \%$ for coated samples with $2 \% \mathrm{ZrO}_{2}$. Also, the results showed a reduction in the porosity and water absorption of all coated samples, having highest scores obtained from the coated samples with $2 \% \mathrm{MgO}$. While the total water absorption rate decreased by $45 \%$ and the density had increased by $1 \%$ and the porosity had decreased by $46 \%$. Additionally, the results of microstructural tests revealed pattern and images for each of SEM and XRD. Also, results indicated that the nano coating leads to significant consumption of Portlandite

ARTICLE INFO

Article history:

Received: 19 September 2020

Accepted: 25 September 2020

Published: 22 January 2021 structure of $\mathrm{CSH}$ and reduction of voids, and this is evident from the enhancement in the physical properties.
\end{abstract}

DOI: https://doi.org/10.47836/pjst.29.1.20

E-mail addresses:

ali_isam@ymail.com (Isam Mohamad Ali)

ahmednamesamir@gmail.com (Tholfekar Habeeb Hussain)

ahmednamesamir@yahoo.com (Ahmed Samir Naje)

* Corresponding author
Keywords: Abrasion resistance, cement composites, hardness, microstructure, nano coating, porosity 


\section{INTRODUCTION}

Harmful agents present in the medium that concrete is subjected to, were the main reasons for degradation and low service life of concrete. Sulfates, carbon dioxide and chlorides from industrial and marine environments penetrate into pores and react chemically, causing expansive reactions and corrosion of steel bars (Quraishi et al., 2017). However, the porosity of the cement- based composites is influenced by many factors that may be due to its raw materials, the production procedure, and water / cement ratio, type of curing, compaction, and degree of hydration (de la Cruz Barroso et al., 2015). According to what was mentioned by Mehta and Monteiro (2006), "the empty pores present in the concrete could be classified according to their size to: gel pores: of 1 to $5 \mu \mathrm{m}$ diameter; capillary pores: of 5 to $30 \mu \mathrm{m}$ diameter; small air bubbles; of $30 \mu \mathrm{m}$ to $1 \mathrm{~mm}$ diameter; and large air bubbles: of greater than or equal to $1 \mathrm{~mm}$ diameter". The absorption rate investigated on concrete is governed by the capillary pressure of its pores, which is determined by the diameter, shape and connection of the pores present in the surface (Pellegrini-Cervantes et al., 2013). In the case of ion penetration, the capillary absorption of concrete is a very fast process, being considered a hundred times faster than its permeability (Aperador et al., 2016). The dispersion method impact for $\mathrm{CaCO}_{3}$ nanoparticles on hydration rate, setting, and compressive strength of concrete. Nanoparticles can be used to increase the mechanical features of cement composites (Camiletti et al., 2013). Another study was made to assess the capability of concrete containing nano $\mathrm{TiO}_{2}$ to degrade organic molecules. The extent of nano $\mathrm{TiO}_{2}$ in the concrete mixes was $3,6,9,12$, and $15 \%$ by cement weight. The resulting concrete samples were subjected to sunlight for $24,48,72$, and $96 \mathrm{hrs}$. The nano $\mathrm{TiO}_{2}$ extinguish the organic molecules, by reducing the surface permeability and, as a result, resists certain kinds of air pollution (Elia et al., 2018). The compositions of nano coatings are nano powders dissolved in a fluid to reach an excessive surface area to volume ratio (Birgisson et al., 2012). Due to nanoparticles coatings, corrosion resistance, antivirus features are improved due to enhanced properties of hardness, adhesion, and wear (Mendes et al., 2015). In India, this coating technique was extensively utilized in the strengthening of New Delhi wealth Games building (Glenn, 2013). Thus, the use of organic coatings on concrete is the most common withstand method of concrete and reinforcements versus weathering and corrosion (Vera et al., 2013). Further, the inclusion of nano $\mathrm{SiO}_{2}$ as thin film on aggregate surfaces enhances the efficiency of concrete. Mortar formed accompanying to nano $\mathrm{SiO}_{2}$ of 0.32 by wt. \% of cement, as a coating on aggregate surfaces exhibited an average $35 \%$ enhancement in compressive, flexural, and tensile strengths with a decline in chloride permeability (Zhuang \& Chen, 2020). The previous and most nanotechnology researchers' studies were focused on characterizing of concrete when nano particles were added in the concrete during mixing to increase strength (Ltifi et al., 2011; Zhang et al., 2019a; Zhang et al., 2019b; Rezania et al., 2019; Ali et al., 2020). Meanwhile, it is the 
surface pores, which control the rate of entry and movement of detrimental agents that can alter concrete properties and causing a deterioration of its microstructure. Thus, the surface porosity of cement-based composites is vital in the durability of concrete, which is the main characteristic that determines the life for which they were designed. Further, the reason behind using nanomaterials was to enhance mortar performance is that the properties of the particles at the nanoscale are extremely better than the conventional particle size for the same chemical component. This means that novel building materials with superior properties could be produced by using nanoparticles.

The objectives of this research were to study the impact of nano coating on the performance of cement-based composite and to improve the resistance to the chemical as well as biological agent ingress using different types and doses of nanoparticles as coating layer and as a protective shield.

\section{MATERIALS AND METHOD}

\section{Materials Characteristics}

The raw materials used were type I cement, micro silica, fine aggregate, water, and super plasticizer. Ordinary Portland cement, conforming to I.Q.S 5/1984, was used to produce the specimens. Micro silica was used as pozzolanic admixture associated with $124 \%$ pozzolanic strength activity index. Results revealed that micro silica used in this study conformed to the requirements of ASTMC-1240-05 standard. A high range water reducer superplasticizer (Sika ViscoCrete 5930) with a density of $1.095 \mathrm{~g} / \mathrm{cm}^{3}$ was used to increase dispersing of mixes, which had been classified as type G according to ASTM C494-14. The sand conforming to the Iraqi Specification No.45/1984 zone 2, was of $4.75 \mathrm{~mm}$ maximum size. The nano powders in addition to methanol alcohol used in this study were provided by Nanoshel Company (USA), and Table 1 presents their properties according to manufacturing origin.

\section{Experimental Analysis}

In this study, cement based composite boards with a density of $2200 \mathrm{~kg} / \mathrm{m}^{3}$ were made and tested for 28 days following the ASTM C1185-12. In light of past research, the experimental factors were: three different percentages of nanoparticles $(1,1.5$, and $2 \%)$ by cement weight, and nano particle type $\left(\mathrm{TiO}_{2}, \mathrm{MgO}, \mathrm{ZnO}\right.$ and $\mathrm{ZrO}_{2}$ All the cement mixes used in this investigation had a constant water-to-cement ratio of $35 \%$, superplasticizer-to-cement ratio of $1 \%$, the replacement of microsilica by cement weight of $10 \%$, and a cement-tosand ratio of 1:2.75. All samples with dimension $\left(305^{*} 152 * 12 \mathrm{~mm}\right)$, were preserved in the molds covered with wet burlap secured with a plastic sheet for one day to prevent moisture loss. After 28 days of moist curing, coating suspensions were prepared following 
the procedure described by Ibrahim (2016). Using airbrush spray gun technique at $10 \mathrm{bar}$ compressed air at laboratory temperature, sprayed distance $25 \mathrm{~cm}$, feeding rate $300 \mathrm{ml} /$ min and primary heating of the specimens to $100{ }^{\circ} \mathrm{C}$ before coating for 30 minutes to improve the bond between the coating layer and the substrate surface. After that, density, water absorption and porosity were determined in accordance to ASTM C642-06 using the water displacement method.

Table 1

The properties of used materials according to Nanoshel Company (USA)

\begin{tabular}{lccccc}
\hline Properties & $\begin{array}{c}\text { Titanium } \\
\text { dioxide nano } \\
\text { powder }\end{array}$ & $\begin{array}{c}\text { Zirconium } \\
\text { oxide nano } \\
\text { powder }\end{array}$ & $\begin{array}{c}\text { Zinc oxide } \\
\text { nano } \\
\text { powder }\end{array}$ & $\begin{array}{c}\text { Magnesium } \\
\text { oxide nano } \\
\text { powder }\end{array}$ & $\begin{array}{c}\text { Methanol } \\
\text { Alcohol }\end{array}$ \\
\hline Chemical composition & $\mathrm{TiO}_{2}$ & $\mathrm{ZrO}_{2}$ & $\mathrm{ZnO}$ & $\mathrm{MgO}$ & $\mathrm{CH}_{3} \mathrm{OH}$ \\
Purity (\%) & 99.9 & 99.9 & 99.9 & 99.9 & 99.8 \\
particle size $(\mathrm{nm})$ & 50 & 50 & 50 & 50 & $/$ \\
Specific surface area $\left(\mathrm{m}^{2} / \mathrm{gm}\right)$ & 35 & 45 & 65 & 40 & $/$ \\
Color & White & White & White & White & colorless \\
Phase & Rutile & Tetragonal & Hexagonal & Cubic & liquid \\
Density $\left(\mathrm{g} / \mathrm{cm}^{3}\right)$ & 4.3 & 5.9 & 5.6 & 3.6 & 0.79 \\
\hline
\end{tabular}

The abrasion test machine consists of rotating disc made of tool steel carried out by four parameters (load, time, sliding speed, and sliding distance). Applied load was 5 $\mathrm{N}$, applied time was $1 \mathrm{~min}$, and the constant sliding speed was $1000 \mathrm{rpm}$ with constant sliding distance of $5 \mathrm{~cm}$ following ASTM C779-03. Vickers micro hardness tester was used to measure the hardness at indentation load of $0.1 \mathrm{~N}$ for 15 second. Four values for the hardness were taken on each specimen surface and the average diagonal dimensions of this indent were measured to find the Vickers hardness according to ASTM E 384-99. In addition, the microstructural properties were investigated in terms of X-ray diffraction (XRD), and scanning electron microscope (SEM), for all coated and control specimens.

\section{RESULTS AND DISCUSSION}

\section{Effect of Nano Coating on Vickers Hardness}

The trends observed during the testing were similar to those seen by other researchers using the same nano particles. The increase observed was almost linear in nature for $\mathrm{TiO}_{2}, \mathrm{ZnO}$ and $\mathrm{ZrO}_{2}$ and nonlinear for $\mathrm{MgO}$ nano particles. Figure 1 demonstrates the correlation between Vickers hardness and nano particle type for both coated and control specimens. Higher hardness for coated cement composite specimens were directly related to their higher dosage in the coating film. When comparing between nano particles types, $\mathrm{ZrO}_{2}$ specimens yielded $29 \%$ higher hardness with the higher dosage in the coating film, despite 
of convergence of results. Whilst $\mathrm{ZnO}$ specimens yielded only $13 \%$ higher hardness as compared to control specimens. Zirconium oxide nano powder yielded the highest values of hardness due to both the accelerated pozzolanic activity between nano oxides and calcium hydroxide from cement hydration, which led to harder products and to the filling effect by the very tiny particles, thus reducing the number and size of surface pores. This trend is similar to that found by Ibrahim (2016).

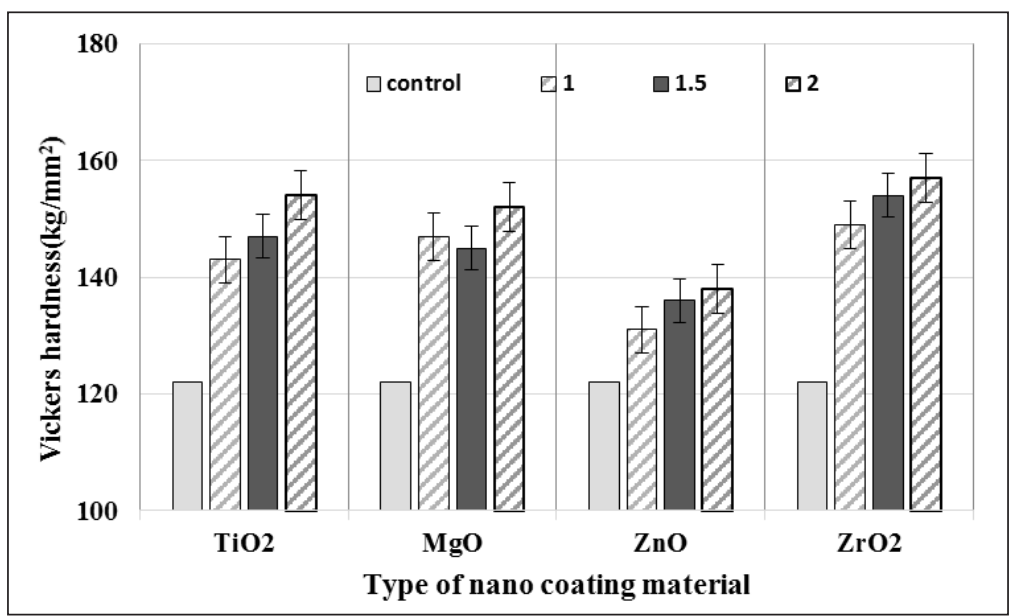

Figure 1. Effect of nanoparticles on the Vickers micro hardness for all cement specimens

\section{Effect of Nano Coating on Abrasion}

The word abrasion mainly points to dry wearing action, like in case of wear on pavements and concrete floors by vehicles. There is an essential inverse correlation between porosity and strength of all solid materials. Figure 2 shows histogram of the abrasion test results for all specimens after 28 days of curing. From Figure 2, it can be seen that the abrasion rate reached to the half of control specimen and often quarter that after coating by $2 \% \mathrm{ZrO}_{2}$, as compared with that of the control. It is also obvious that higher doses of $2 \%$ for all types were very beneficial to long term abrasion rate and, the lowered $1 \%$ dose might be more desirable than high rate for economy consideration, hence decreasing the abrasion rate of the final composite. This could be due to the filling effect by the very tiny particles which reduced the volume and number of surface pores resulting in solidification of specimen surface. Moreover, as compared to control, an increase in the nano particles concentration in the coating film from ( 1 to $2 \%$ ) decreased the abrasion rate by (21-28\%), (14-26\%), (9$23 \%$ ) and (28-39\%) for $\mathrm{TiO}_{2}, \mathrm{MgO}, \mathrm{ZnO}$ and $\mathrm{ZrO}_{2}$, respectively. It was also noticed $1 \%$ $\mathrm{ZnO}$ showed the lower decrease in the abrasion of $39 \mathrm{~g} / \mathrm{min} * 10-8$, while $1 \% \mathrm{ZrO}_{2}$ nano particles showed the higher decrease of $26 \mathrm{~g} / \mathrm{min} * 10^{-8}$. This trend is comparable to that found by Othman et al., (2016). 


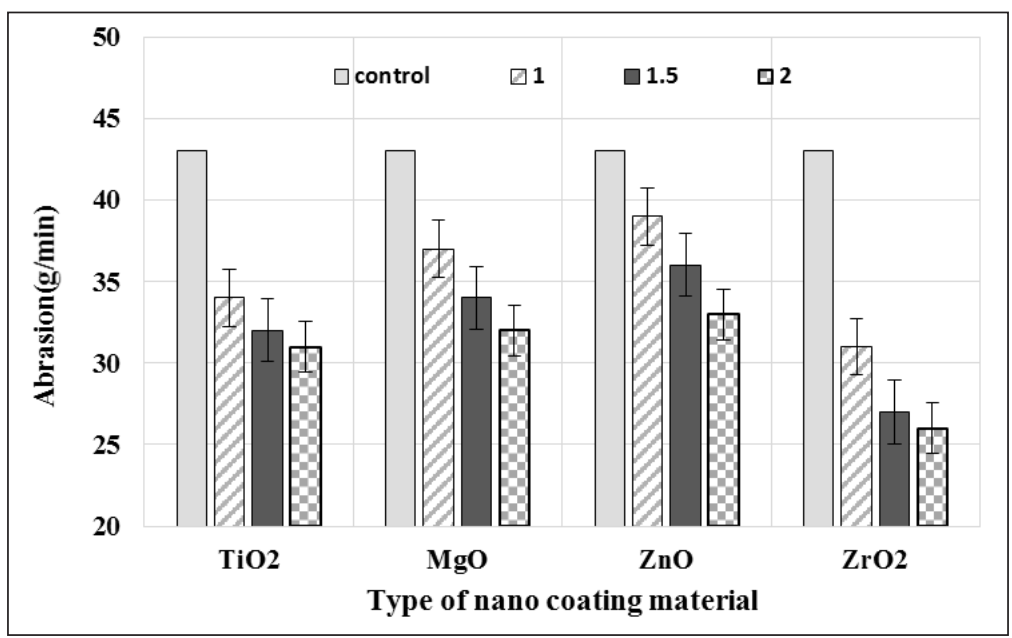

Figure 2. Effect of nanoparticles on the abrasion rate for all cement specimens

\section{Effect of Nano Coating on Density}

Figure 3 shows the average densities of all specimens after 28 days of curing. As discussed above, all of the mechanical properties calculated improved as the nano content increased in the coating film. The density for each nano particle type varied differently depending on the percentage of their mass addition in the coating film and to the density of each type. According to Figure 3, all coated specimens were heavier than the control, especially for $2 \%$ zirconium oxide nano particles which had the highest density of $2.262 \mathrm{~g} / \mathrm{cm}^{3}$. This could be attributed to the high density of $\left(\mathrm{ZrO}_{2}\right)$ compared to other types. Else ways, $2 \%$ $(\mathrm{MgO})$ showed the lower improvement in density in comparison to control due to the low density of nano $\mathrm{MgO}$ particles. However, all the nano coated films showed pozzolanic reactivity between nano oxides and calcium hydroxide from cement hydration leading to

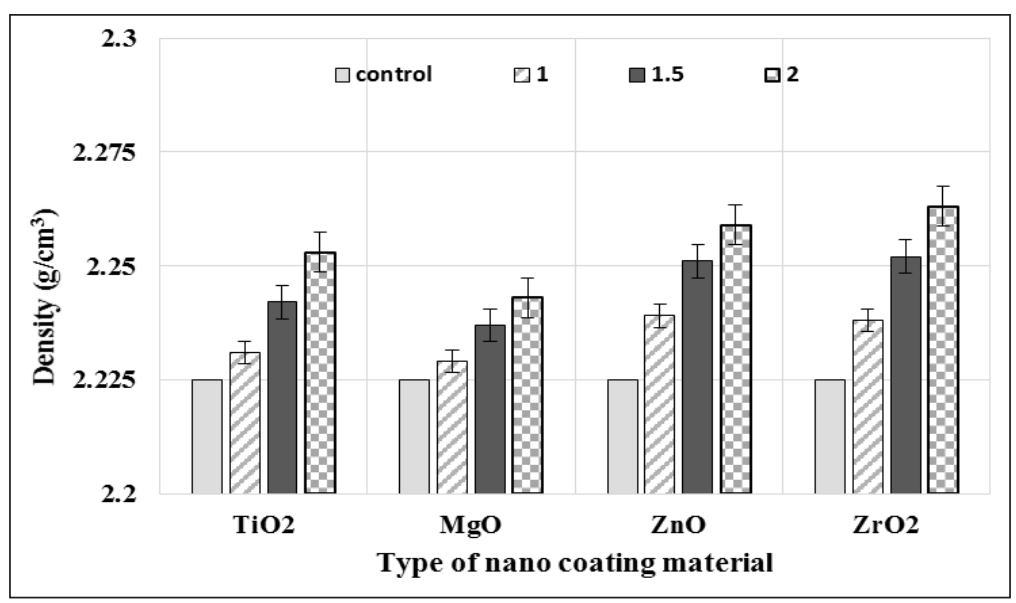

Figure 3. Effect of nanoparticles on the density for all cement specimens 
further hydration products that altered the final density. Hence, increasing the nano particle dosage in the coating film ( 1 to 1.5 to $2 \%$ ) increased the density of specimen $0.3,0.8 \&$ $1.3 \%$ for $\mathrm{TiO}_{2} ; 0.2,0.5 \& 0.8 \%$ for $\mathrm{MgO} ; 0.6,1.2 \& 1.5 \%$ for $\mathrm{ZnO} ; 0.6,1.2 \& 1.7 \%$ for $\mathrm{ZrO}_{2}$. These results are in line with the values obtained by Khitab and Arshad (2014).

\section{Effect of Nano Coating on Porosity}

From Figure 4, it is observed that all coated specimens would show lower porosity especially $\mathrm{MgO}$ at $2 \%$ by weight of cement. A stronger adhesion between the coating film and the substrate surface besides the low density of nano $\mathrm{MgO}$ particles was assumed to be responsible for this. At higher doses, there would be a chemical interaction between the coating film and the specimen surface that filled the empty pores on the surface and beyond. However, the ability of mineral nano oxides to react at normal temperatures with $\mathrm{CH}$ (present in the hydrated Portland cement) and to form additional calcium silicate hydrate were responsible for the decrement in porosity of the final composite. As shown in Figure 4 , all coated specimens had porosities in the range of 8-45\%, which was smaller than that of control without coating film. It was interesting to find that there existed a reverse linear relationship between the nano particle dosage in the coating film and the void ratio. The lowest porosity was achieved in $2 \% \mathrm{MgO}(1.92 \%)$, and the highest was gained for $\mathrm{ZrO}_{2}$ $(3.26 \%)$ at $1 \%$ dose of addition.

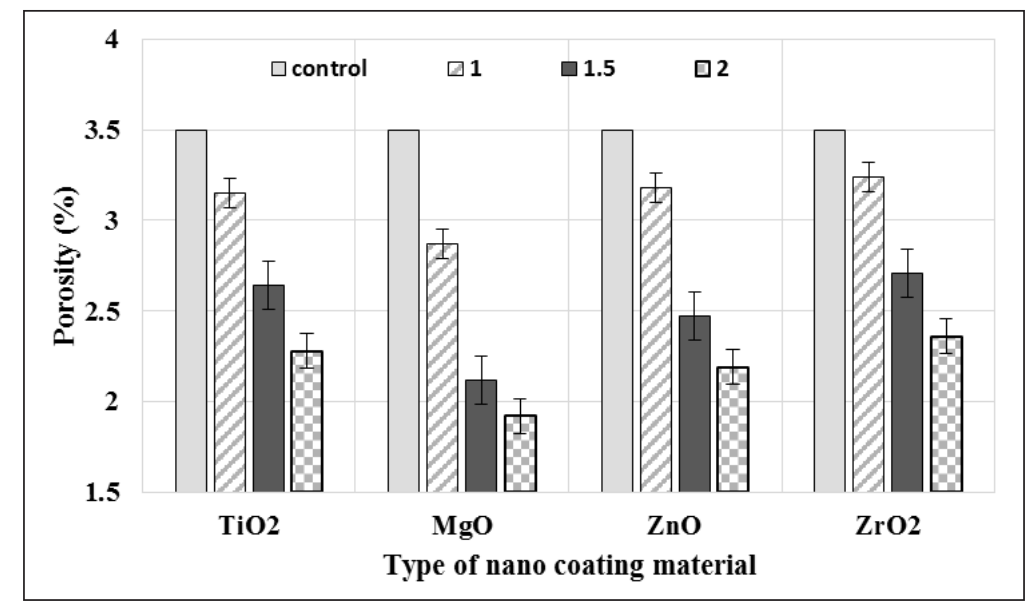

Figure 4. Effect of nanoparticles on the porosity for all cement specimens

\section{Effect of Nano Coating on Water Absorption}

Figure 5 represents the water absorption of all cement coated and the control specimens after 28 days of curing. It is obvious that the water absorption for all coated specimens was lower than the control, particularly for nano $\mathrm{MgO}$ coating of $2 \%$ has the lowest water absorption (45\%) as compared to control. This could be attributed to the low density of nano 
$\mathrm{MgO}$ particles leading to higher volume fraction in the coating film which decreased the surface porosity of specimens. Meanwhile, the lowest water absorption for $2 \% \mathrm{TiO}_{2}, \mathrm{ZnO}$ and $\mathrm{ZrO}_{2}$ were 34, 37 and $31 \%$ respectively. Test results indicated that the water absorption of all specimens decreased continuously with increasing the nano particles dosage in the coating film. This could be due to the filling effect by the very tiny particles which reduced the volume and number of surface pores. Nevertheless, additional hydration products were gained during the pozzolanic activity between nano oxides and calcium hydroxide from cement hydration as indicated in SEM and XRD images.

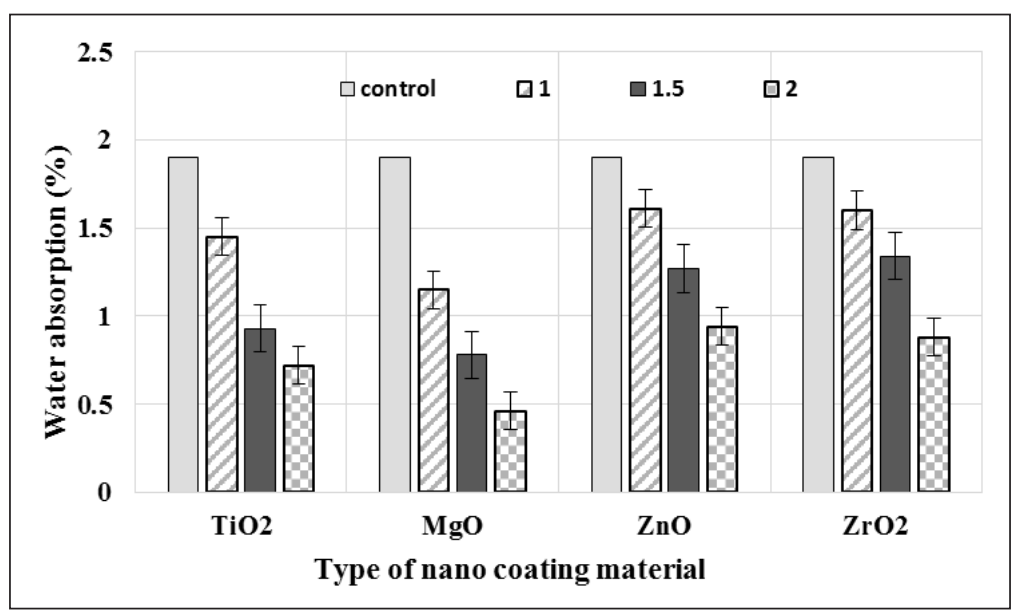

Figure 5. Effect of nanoparticles on the water absorption for all cement specimens

\section{XRD Patterns}

After 28 days of curing, XRD analyses were conducted to investigate the activity of incorporating nanoparticles for control and coated cement composite specimens. According to "Joint Committee on Powder Diffraction Standards (JCPDS)", the components shown in the Figure 1 to 6 were: Portlandite: $\mathrm{Ca}(\mathrm{OH})_{2}$, hexagonal crystallized, Tobermorite: $\mathrm{Ca}_{5} \mathrm{Si}_{6}$ $(\mathrm{O}, \mathrm{OH}, \mathrm{F})_{18} .5 \mathrm{H}_{2} \mathrm{O}$, orthorhombic crystallized, Ettringite: $\mathrm{Ca}_{6} \mathrm{~A}_{12}\left(\mathrm{SO}_{4}\right)_{3}(\mathrm{OH})_{12} .26 \mathrm{H}_{2} \mathrm{O}$, hexagonal crystallized, CSH: $\mathrm{CaO} . \mathrm{SiO}_{2} \cdot \mathrm{H}_{2} \mathrm{O}$, poor crystallized, $\mathrm{CS}$ : $\mathrm{CaSiO}_{3}$, monoclinic crystallized, Zirconium Oxide: $\mathrm{ZrO}_{2}$, tetragonal crystallized, Titanium Dioxide: $\mathrm{TiO}_{2}$, rutile, Magnesium Oxide: $\mathrm{MgO}$, cubic crystallized, and Zinc Oxide: $\mathrm{ZnO}$, hexagonal crystallized. The results of the X-ray diffraction spectra presented in Figure 6 to 10 include data from representative mixtures from the testing matrix control and coated with four types of nano powders. According to Figure 6, major peak humps of $\mathrm{Ca}(\mathrm{OH})_{2}$ was observed in the diffraction pattern $2 \Theta$ values of $21.5^{\circ}, 29.5^{\circ}$ and $37^{\circ}$ for control mixes. Meanwhile, a minor peak of ( $\mathrm{CSH}, \mathrm{CS}$ and ettringite) were noticed in the diffraction pattern between $2 \Theta$ values of $22^{\circ}, 25^{\circ}$ and $52^{\circ}$. It is also evident from XRD patterns in Figures 7 to 10 that the $\mathrm{CH}$ intensity decreased with the $\mathrm{ZrO}_{2}, \mathrm{TiO}_{2}, \mathrm{MgO}$, and $\mathrm{ZnO}$ coated nanoparticles. 
However, the results are agreeable with those of obtained by Ahmed et al. (2017). It is therefore concluded from Figure 7 to 10 that the nanoparticles chemically reacted with $\mathrm{CH}$ produced during the hydration of cement. The pozzolanic reactivity of nanoparticles can significantly improve the microstructure, so enhancing the mechanical performance of the cement composites (Othman et al., 2016).

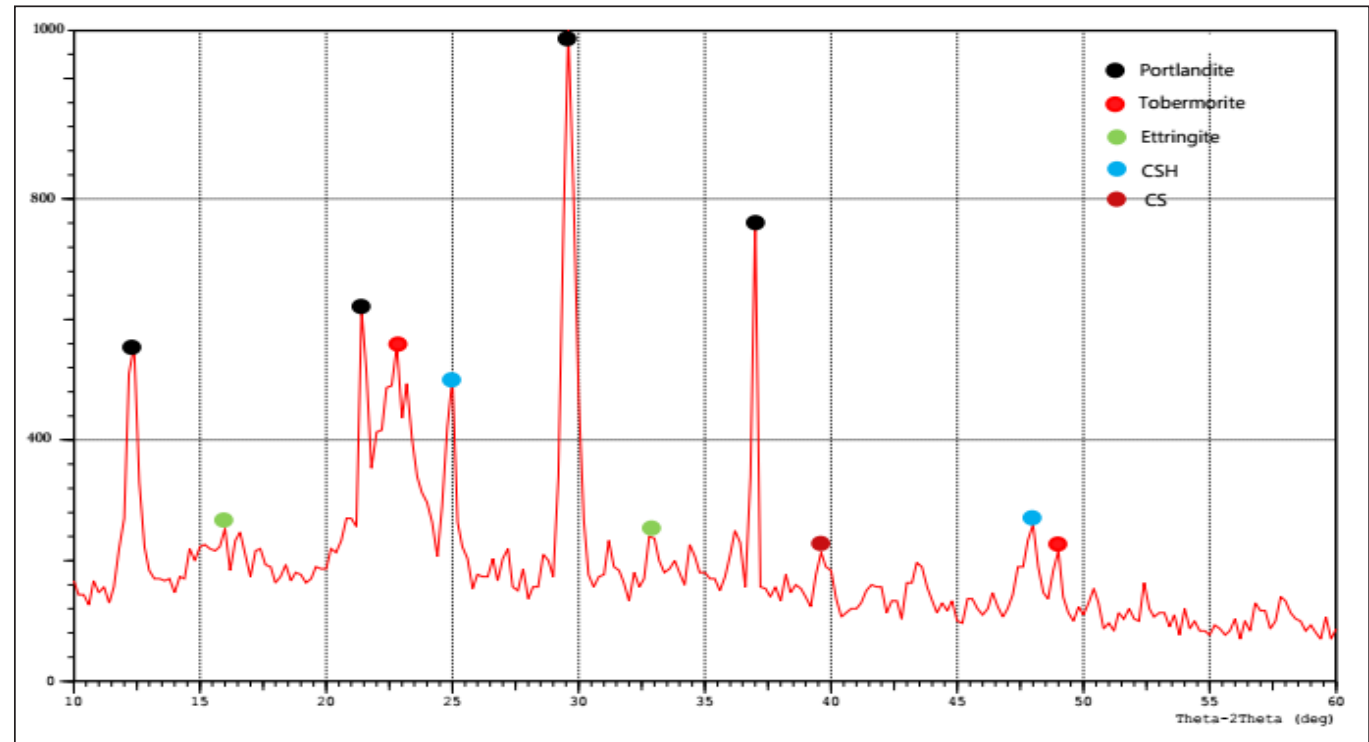

Figure 6. The XRD patterns for the control cement specimen

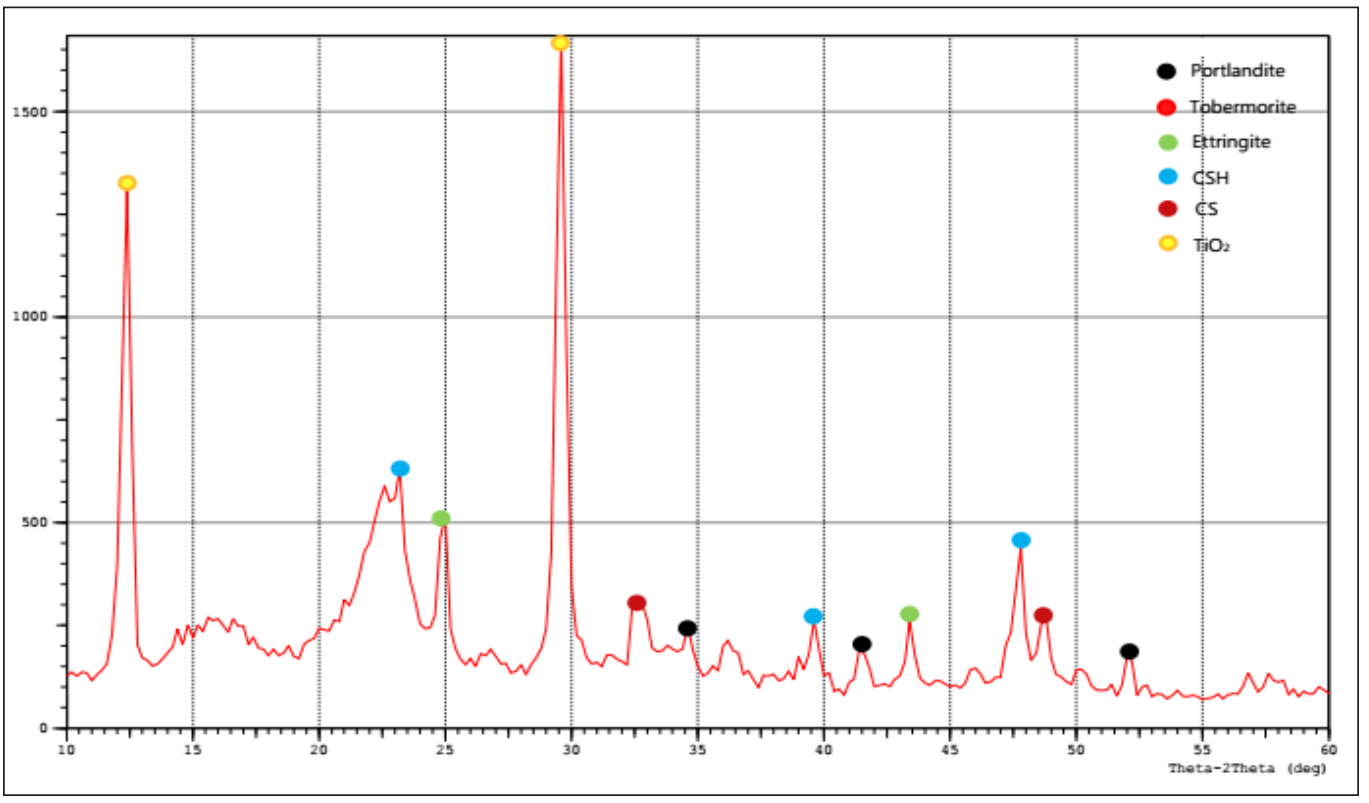

Figure 7. The XRD patterns for the cement coated specimen with $2 \% \mathrm{TiO}_{2}$ nanoparticles 


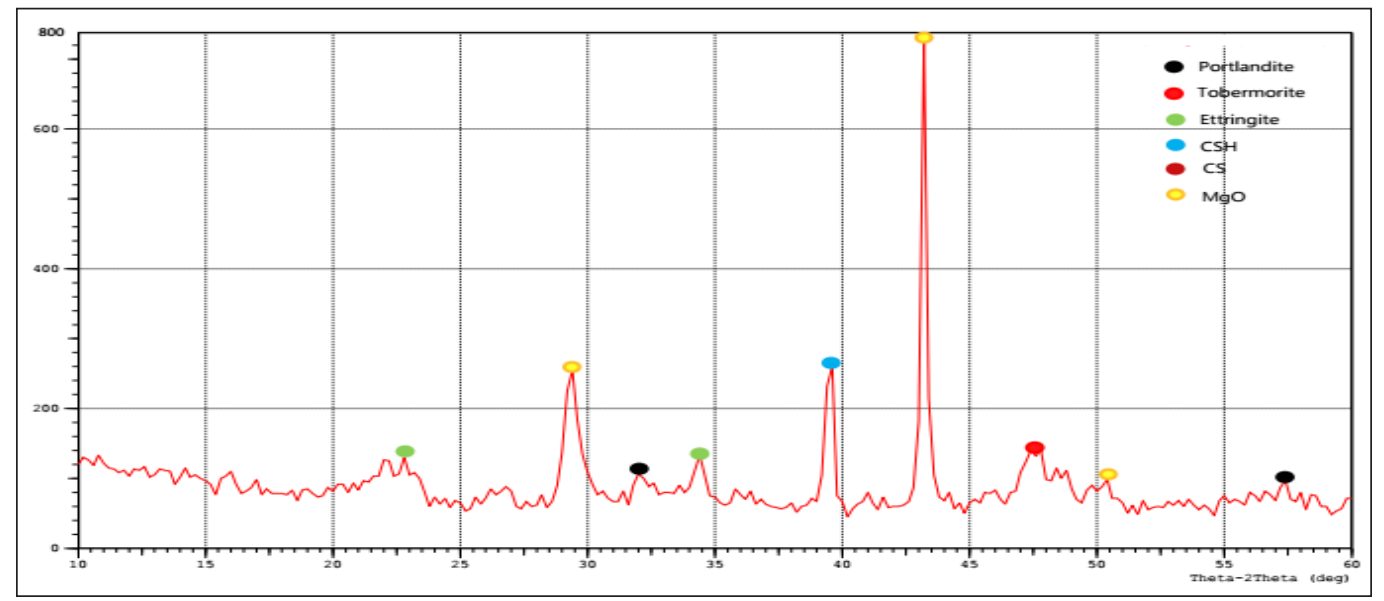

Figure 8 . The XRD patterns for the cement coated specimen with $2 \% \mathrm{MgO}$ nanoparticles

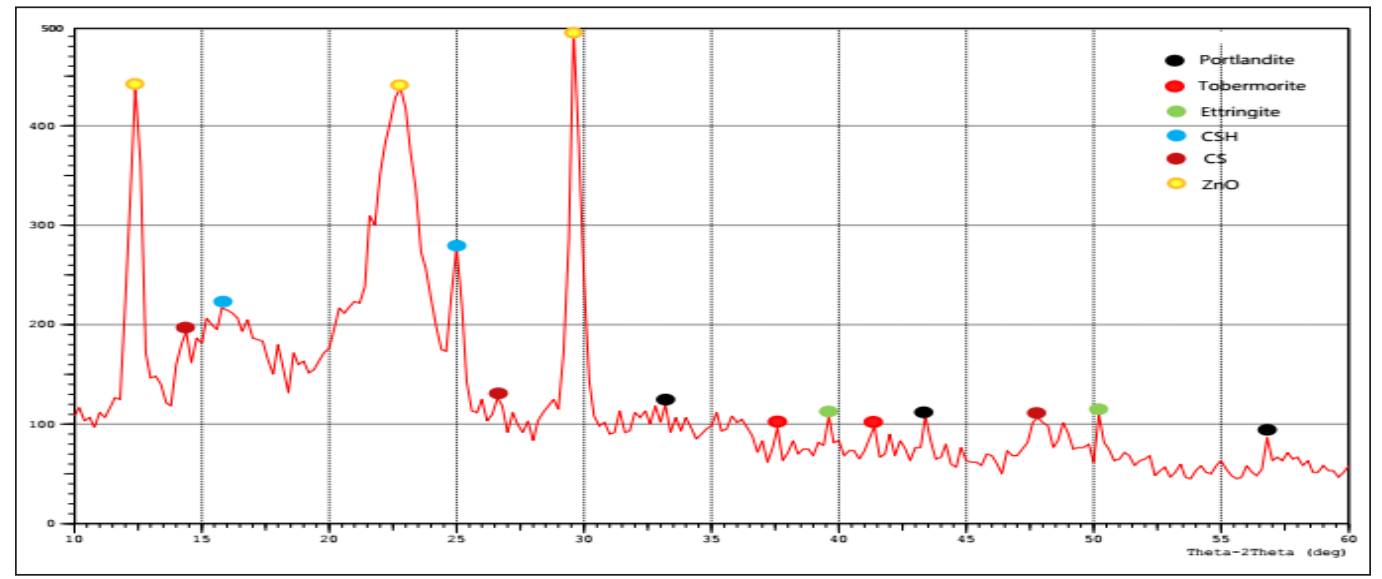

Figure 9. The XRD patterns for the cement coated specimen with $2 \% \mathrm{ZnO}$ nanoparticles

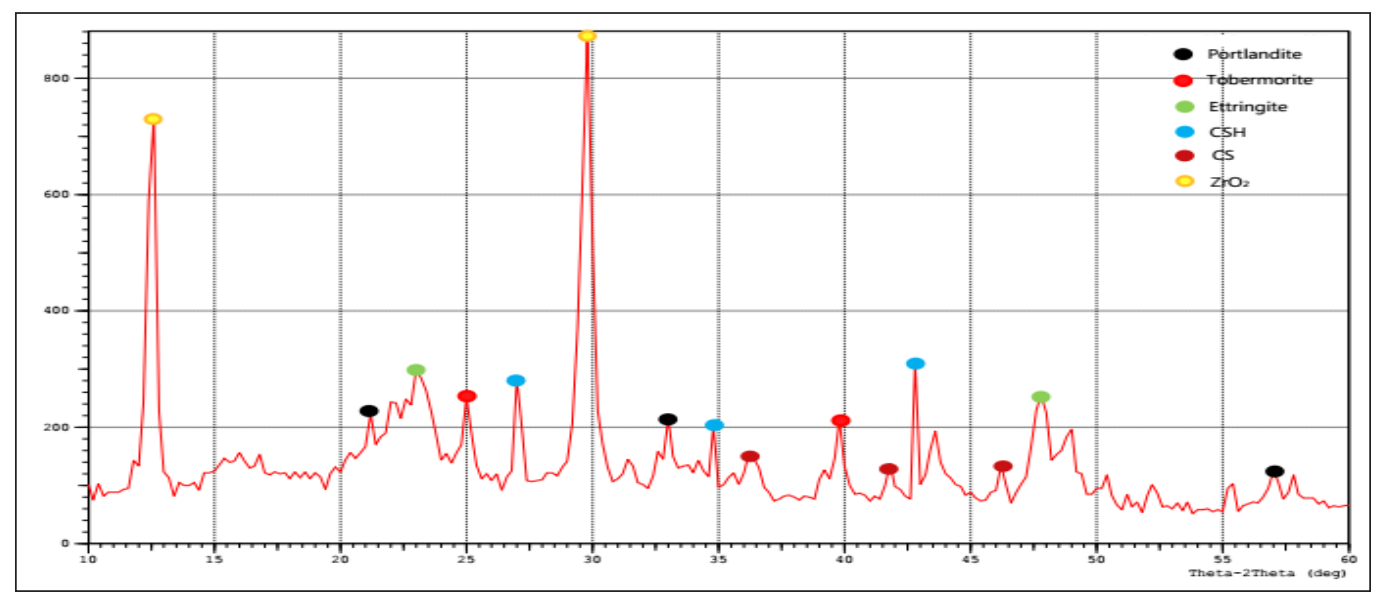

Figure 10. The XRD patterns for the cement coated specimen with $2 \% \mathrm{ZrO}_{2}$ nanoparticles 


\section{SEM Analysis}

SEM analysis of the cementitious composites offered a good qualitative view of the mineralogy that lies inside the composite structure. Figure 11 views the SEM micrographs of control and coated with four types of nano powders fractured surface after 28 days of moist curing. Four representative images for each specimen were obtained and only one SEM micrograph was chosen from them. The existence of $\mathrm{CH}$ crystals connected to the $\mathrm{CSH}$ gel (arrow 1/a) indicates that the microstructure was weak and also explains the reduction of mechanical properties for the control mix. Whereas it seems clear that the surface pores were partially filled with $2 \% \mathrm{TiO}_{2}$ nano particles and/or additional hydration products from the pozzolanic activity (arrow 2/b). Also, it is obvious that after $2 \% \mathrm{MgO}$ nano coating, there was a good adhesion force between CSH and CS, so no cracks appeared within ITZ (arrows $3 / \mathrm{c}$ ). However, the cross section of $2 \% \mathrm{ZnO}$ used here, was composed of large crystals of $\mathrm{CH}$, so the fracture crack at failure initiated rapidly within ITZ so reducing the final composite strength (arrows $4 / \mathrm{d}$ ). This is an indication of low pozzolanic activity for Zinc oxide nano powder. This is the opposite of what happened to the composite after $\mathrm{ZrO}_{2}$ nano coating (arrows 5/e). The surface black holes were completely filled with extra $\mathrm{CSH}$ from the pozzolanic activity and there was no indication for $\mathrm{CH}$ crystals in

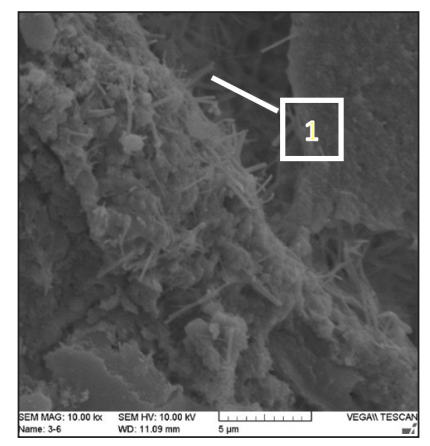

(a)

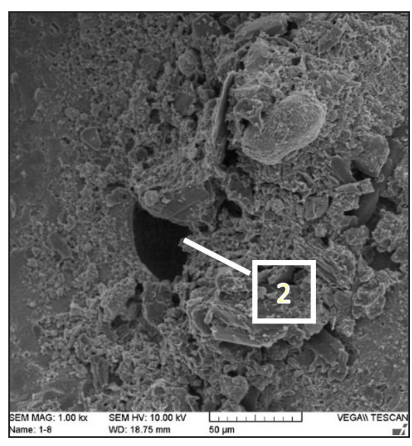

(b)

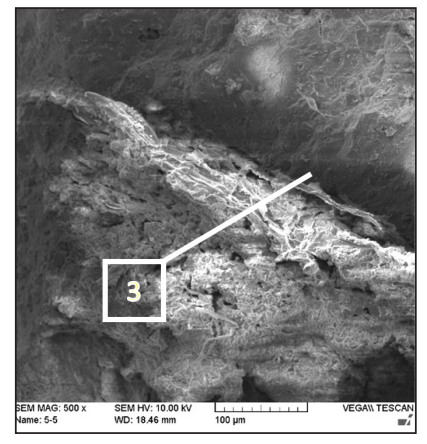

(c)

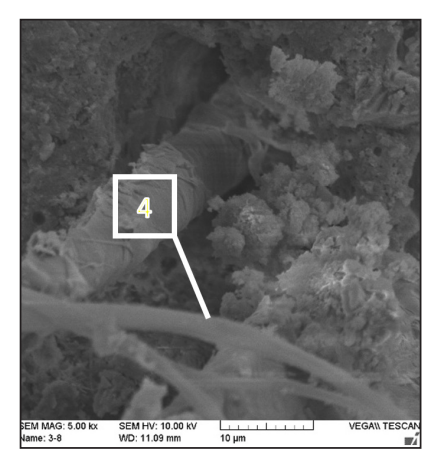

(d)

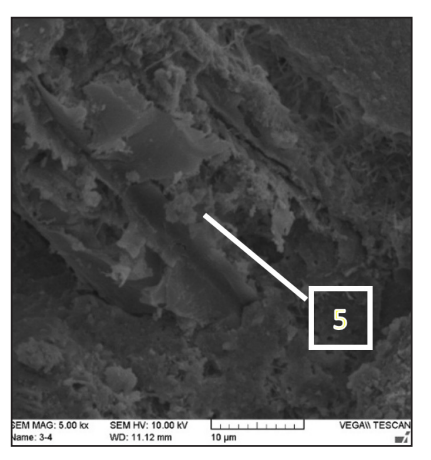

(e)

Figure 11. SEM images of fractured surface at 28-day for specimens: (a) control; (b) coated with $2 \% \mathrm{TiO}_{2}$; (c) coated with $2 \% \mathrm{MgO}$; (d) coated with $2 \% \mathrm{ZnO}$ and (e) coated with $2 \% \mathrm{ZrO}_{2}$ 
the morphology. Therefore, the coated cement matrix is denser than control mix that can enhance the interfacial transition zone, and certainly promote the strength and density of the end composite. The results are in accordance with prior work done by Du et al. (2019).

\section{CONCLUSION}

Based on the analysis of data compiled throughout this study, these conclusions are summarized as follows:

1. Higher hardness was observed for coated specimens that directly related to their higher dosage in the coating film. $2 \% \mathrm{ZrO}_{2}$ yielded $29 \%$ the superior hardness whilst, $\mathrm{ZnO}$ specimens yielded only $13 \%$ higher hardness as compared to control.

2. The abrasion rate reduced after coating by nano particles, as compared to control. Higher doses of $2 \%$ for all types were very beneficial to long term abrasion rate, thereby decreasing the abrasion rate of the final composite.

3. All coated specimens were heavier than the control, especially for $2 \% \mathrm{ZrO}_{2}$ nano particles which had the highest density of $2.262 \mathrm{~g} / \mathrm{cm}^{3}$.

4. All coated specimens showed lower porosity, especially $\mathrm{MgO}$ at $2 \%$ by weight of cement due to both the accelerated pozzolanic activity between nano oxides and calcium hydroxide and to the filling effect by the very tiny particles leading to the reduction in the number and size of pores.

5. $2 \% \mathrm{MgO}$ coating had the highest water absorption (45\%) as compared to control. Meanwhile, the water absorption for $2 \% \mathrm{TiO}_{2}, \mathrm{ZnO}$ and $\mathrm{ZrO}_{2}$ were 34, 37 and $31 \%$ respectively.

6. It was evident from XRD patterns that the $\mathrm{CH}$ intensity decreased with the coated $\mathrm{ZrO}_{2}, \mathrm{TiO}_{2}, \mathrm{MgO}$, and $\mathrm{ZnO}$ nanoparticles.

7. The surface black holes were completely filled with nano particles and/or extra $\mathrm{CSH}$ from the pozzolanic activity and there was no indication for $\mathrm{CH}$ crystals in the morphology except for $\mathrm{ZnO}$.

8. $\mathrm{ZrO}_{2}$ was the best nano material that improve the performance of cement-based composites. For economic consideration, $1.5 \%$ was the preferable dose that maximize the performance of cement-based composites. Over this dose (2\%) a low improvement was noticed.

\section{ACKNOWLEDGEMENT}

The authors thank the Kerbala Technical Institute, Al-Furat Al-Awsat Technical University for helping in the preliminary examination of raw materials. 


\section{REFERENCES}

Ahmed, H. E. D., Sabrah, B. A. E. G., Mohamed, S. A. E. A., \& Mostafa, N. M. (2017). Chemical and engineering properties of blended cement containing micro-and nano-silica. American Journal of Chemical Engineering, 5(5), 111-121. doi: 10.11648/j.ajche.20170505.13

Ali, I. M., Nasr, M. S., \& Naje, A. S. (2020). Enhancement of cured cement using environmental waste: particleboards incorporating nano slag. Open Engineering, 10(1), 273-281. doi: https://doi.org/10.1515/ eng-2020-0031

Aperador, W., Delgado, A., \& Bautista-uiz, J. (2016). Effect of durability and chloride ion permeability in ternary cementitious concrete with additions of fly ash and blast furnace slag. International Journal of Electrochemical Science, 11, 2297-2305.

Birgisson, B., Mukhopadhyay, A. K., Geary, G., Khan, M., \& Sobolev, K. (2012). Nanotechnology in concrete materials: A synopsis. Washington, USA: Transportation Research Board. doi: 10.17226/22672

Camiletti, J., Soliman, A. M., \& Nehdi, M. L. (2013). Effect of nano-calcium carbonate on early-age properties of ultra-high-performance concrete. Magazine of Concrete Research, 65(5), 297-307. doi: https://doi. org/10.1680/macr.12.00015

de la Cruz Barroso, J. C., del Campo, J. M., \& Aranguren, D. C. (2015). Comparative study on porosity and permeability of conventional concrete and concrete with variable proportions of natural zeolite additions. Revista de la Construcción, 14(3), 72-78.

Du, S., Wu, J., AlShareedah, O., \& Shi, X. (2019). Nanotechnology in cement-based materials: A review of durability, modeling, and advanced characterization. Nanomaterials, 9(9), 1-29. doi: https://doi. org/10.3390/nano9091213

Elia, H. N., Ghosh, A., Akhnoukh, A. K., \& Nima, Z. A. (2018). Using nano- and micro-titanium dioxide $\left(\mathrm{TiO}_{2}\right)$ in concrete to reduce air pollution. Journal of Nano Medicine and Nanotechnology, 9(3), 1-5. doi: $10.4172 / 2157-7439.1000505$

Glenn, J. (2013). Nanotechnology in concrete: Critical review and statistical analysis (MSc Thesis). Florida Atlantic University, Boca Raton, Florida.

Ibrahim, S. I. (2016). Studying the effect of nano additives materials in cement coating for building applications (PhD Thesis). University of Technology, Baghdad, Iraq.

Khitab, A., \& Arshad, M.T. (2014). Nano construction materials: Review. Reviews on Advanced Materials Science, 38(2), 181-189.

Ltifi, M., Guefrech A., Mounanga P., \& Khelidj A. (2011). Experimental study of the effect of addition of nano-silica on the behavior of cement mortars. Procedia Engineering, 10, 900-905. doi: https://doi. org/10.1016/j.proeng.2011.04.148

Mehta, P. K., \& Monteiro, P. J. (2006). Concrete microstructure, properties, and materials (3rd Ed.). New York, USA: McGraw-Hill.

Mendes, T. M., Hotza, D., \& Repette, W. L. (2015). Nanoparticles in cement based materials: A review. Revision Advance Materials Science, 40(1), 89-96. 
Othman, F. M., Hameed, A. A., \& Ibrahim, S. I. (2016). Studying the effect of nano additives and coating on some properties of cement mortar mixes. Engineering and Technology Journal, 34(3 Part (A) Engineering), 553-566.

Pellegrini-Cervantes, M. J., Almeraya-Calderon, F., Borunda-Terrazas, A., Bautista-Margulis, R. G., ChacónNava, J. G., Fajardo-San-Miguel, G., ... \& Martinez-Villafañe, A. (2013). Corrosion resistance, porosity and strength of blended portland cement mortar containing rice husk ash and nano- $\mathrm{SiO}_{2}$. International Journal of Electrochemical Science, 8(1), 10697-10710.

Quraishi, M. A., Nayak, D. K., Kumar, R., \& Kumar, V. (2017). Corrosion of reinforced steel in concrete and its control: An overview. Journal of Steel Structures and Construction, 3(1), 1-6.

Rezania M., Panahandeh M., Razavi S. M. J., \& Berto F. (2019). Experimental study of the simultaneous effect of nano-silica and nano-carbon black on permeability and mechanical properties of the concrete. Theoretical and Applied Fracture Mechanics, 104, 1-10. doi: https://doi.org/10.1016/j.tafmec.2019.102391

Vera, R., Apablaza, J., Carvajal, A. M., \& Vera, E. (2013). Effect of surface coatings in the corrosion of reinforced concrete in acid environments. International Journal of Electrochemical Science, 8, 11832-11846.

Zhang, A., Ge Y., Yang, W. C., Cai, X. P., \& Du, Y. B. (2019a). Comparative study on the effects of nano-SiO nano- $\mathrm{Fe}_{2} \mathrm{O}_{3}$ and nano-NiO on hydration and microscopic properties of white cement. Construction and Building Materials, 228, 1-11. doi: https://doi.org/10.1016/j.conbuildmat.2019.116767

Zhang, S., Qiao, W. G., Chen, P. C., \& Xi, K. (2019b). Rheological and mechanical properties of microfinecement-based grouts mixed with microfine fly ash, colloidal nanosilica and superplasticizer. Construction and Building Materials, 212, 10-18. doi: https://doi.org/10.1016/j.conbuildmat.2019.03.314

Zhuang, C., \& Chen, Y. (2020). The effect of nano- $\mathrm{SiO}_{2}$ on concrete properties: A review. Nanotechnology Review, 8, 562-572. doi: https://doi.org/10.1515/ntrev-2019-0050 